\title{
Cable Replacement Considering Optimal Wind Integration and Network Reconfiguration
}

DOI:

10.1109/TSG.2017.2696340

\section{Document Version}

Accepted author manuscript

Link to publication record in Manchester Research Explorer

\section{Citation for published version (APA):}

Levi, V., Buhari, M., \& Kapetanaki, A. (2018). Cable Replacement Considering Optimal Wind Integration and Network Reconfiguration. IEEE Transactions on Power Systems, 9(6), 5752-5763.

https://doi.org/10.1109/TSG.2017.2696340

\section{Published in:}

IEEE Transactions on Power Systems

\section{Citing this paper}

Please note that where the full-text provided on Manchester Research Explorer is the Author Accepted Manuscript or Proof version this may differ from the final Published version. If citing, it is advised that you check and use the publisher's definitive version.

\section{General rights}

Copyright and moral rights for the publications made accessible in the Research Explorer are retained by the authors and/or other copyright owners and it is a condition of accessing publications that users recognise and abide by the legal requirements associated with these rights.

\section{Takedown policy}

If you believe that this document breaches copyright please refer to the University of Manchester's Takedown Procedures [http://man.ac.uk/04Y6Bo] or contact uml.scholarlycommunications@manchester.ac.uk providing relevant details, so we can investigate your claim.

\section{OPEN ACCESS}




\title{
Cable Replacement Considering Optimal Wind Integration and Network Reconfiguration
}

\author{
Muhammad Buhari, Student Member, IEEE, Victor Levi, Senior Member, IEEE and Alexandra \\ Kapetanaki, Student Member, IEEE
}

\begin{abstract}
This paper proposes a methodology for optimal cable replacement based on utility financial benefits that are calculated by considering the entire network in the planning period. The overall problem is set within a sequential Monte Carlo simulation framework and uses novel reliability modelling of ageing distribution cable using the 'IEC-Arrhenius-Weibull' model. Optimal cable replacement schemes are developed by considering the connection of new wind sources and network reconfiguration to reduce cable ageing and defer its replacement. The core concepts of the proposed methodology are two new mixed-integer non-linear optimization models. The first optimizes the connection of new wind sources by minimizing the connection and reinforcement costs, as well as minimizing the cost of the cable thermal-loss-of-lives in the planning period. In the operations stage, the network is optimally reconfigured to minimize the cost of losses, the thermal-loss-of-life of cable, and reliability. Both optimization models are applicable to radially operated medium voltage networks that are backfed from several normally open points. The final outputs are proposed cable ranking lists for replacement and reliability and cost metrics.
\end{abstract}

Index Terms - Replacement planning, ageing cable, IECArrhenius-Weibull reliability model, optimal wind connection, optimal reconfiguration, thermal loss-of-life.

\section{NOMENCLATURE}

Sets

$\Omega_{D G} \quad$ Pre-specified set of DG units

$\Omega_{\text {nod }}, \Omega_{D G-\text { nod,k }}$ Sets of nodes and potential nodes for DG unit $k$

$\Omega_{n e w-b r, n_{k}} \quad$ Set of potential 'DG branches' for location $n_{k}$

$\Omega_{b r}$

$\Omega_{\text {sub }}$

Set of existing branches

Set of primary substations

Parameters

$A, B$

$t_{p}, t_{q}$

$\operatorname{cost}_{n_{k} i}^{n e w}$

$\operatorname{cost}_{i j}^{\text {rein }}$

$\operatorname{cost}_{k}^{D G}$

$S_{i j}^{r a t}, I_{i j}^{r a t}$

Parameters of the Arrhenius model

Duration of historic period $p$ planning period $q$

Cost to construct new 'DG branch' $n_{k} i$

Cost to reinforce existing branch $i j$

Cost of DG unit $k$ (specific cost $£ /$ MVA times capacity MVA)

$P_{D G_{i}}, Q_{D G_{i}}$

Nominal rating of branch $i j$ in MVA and A

$P_{D_{i}}, Q_{D_{i}}$

Active and reactive power supplied by DG, node $i$

$\bar{I}_{l \jmath} e x, \bar{I}_{l \jmath}{ }^{r e i}, \overline{I_{n_{k} l}}{ }^{n e v}$ Rating of existing, reinforced and new branch

This work was supported by the Nigerian Petroleum Technology Development Fund - PTDF Nigeria.

M. Buhari, V. Levi and A. Kapetanaki are with The University of Manchester, UK (email: muhammad.buhari@postgrad.manchester.ac.uk; victor.levi@manchester.ac.uk; alexandra.kapetanaki@ manchester.ac.uk).

$\begin{array}{ll}V_{i}^{\text {min }}, V_{i}^{\text {max }} & \text { Minimum/ maximum voltage limits at node } i \\ N_{D G}, N_{b} & \text { Number of DG units and existing buses } \\ \text { cost }_{E E}, \operatorname{cost}_{E N S} & \text { Cost of delivered and non-delivered } \mathrm{kWh} \\ R_{i j} & \text { Resistance of branch } i j \\ K_{i} & \text { Fictitious load of } 1.0 \text { at DG nodes; 0 otherwise } \\ C I_{\text {Inc }}, C M L_{\text {Inc }} & \text { Incentive rates for CIs and CMLs } \\ N O_{\text {fail }}, C_{\text {fail }} & \text { Number of failures and cost per failure }\end{array}$

\section{Functions/Variables}

$L(\cdot), \theta_{C}$

$L_{T}, \Delta L_{T}(\cdot)$

$L_{p}(\cdot), L_{q}(\cdot)$

$\theta_{c, p}, \theta_{c, q}$

$\operatorname{COST}_{I N V}$

$\operatorname{COST}_{I N V}^{T O T}$

$y_{n_{k}}$

$c r_{i j}^{r e i n}, c r_{n_{k} i}^{n e w}$

Life measure and conductor temperature

Total and hourly thermal loss-of-life

Life in historic period $p$ and planning period $q$

Conductor temperature in historic period $p$ and planning period $q$

Initial investment cost for DG connection

DG investment cost including loss-of-life cost

Binary decision variable for nodal location of DG $k$

Binary construction variable to reinforce existing branch $i j$ and to construct new 'DG branch' $n_{k} i$

Thermal loss-of-life of cable section $i j$ in planning period

$L^{\prime \prime} T_{i j}$

$O c_{i j}, O c_{n_{k} i}$

Binary operation variable indicating whether branch $i j$ or $n_{k} i$ is closed $(=1)$ or open $(=0)$

$S_{i j}, P_{i j}, Q_{i j}, I_{i j}$

Apparent, active, reactive power and current flow in

branch $i j$ - functions of voltages and angles

Binary decision variable indicating whether the first

$m_{i}$ feeder section is supplied from a primary (node $i$ is MV busbar of the substation)

Active and reactive power supplied by primary substation at node $i$

Equal to 1 for existing nodes and to $y_{n_{k}}$ for new DG nodes

Binary decision variable indicating whether the existing circuit in branch $i j$ is used or not Fictitious power flow in existing branch $i j$ and new 'DG-branch' $n_{k} i$

Hourly cost of loss-of-lives, losses and reliability

Hourly cost of loss-of-lives

Load curtailment and power factor at node $i$

$L C_{i}(\cdot), \cos \varphi$

$\mathrm{COST}_{1}, \mathrm{COST}_{2}$

Costs in planning period used for cable ranking

$\triangle C I, \triangle C M L$

CIs and CMLs associated with a cable section

\section{INTRODUCTION}

Development and operations planning of modern distribution networks needs to consider ever-increasing network stress, as well as regulatory regimes containing restrictions on capital funding and performance driven incentives. Increased network stress is manifested through higher asset loading caused by the growth of general load, 
connection of new low carbon technologies (LCTs) and requirements to apply 'smart' solutions, which often reduce capacity margins. On the other hand, new LCTs and 'smart' solutions provide added flexibility during network operation.

Replacement planning of distribution assets has traditionally been completed on an individual basis without considering system aspects [1]. The replacement fund is typically pre-specified, so that a ranking list of assets for replacement is established and a line is drawn when the available budget is reached. Traditional methods used for asset ranking are based on asset age, failure history and asset 'health indices' $[1,2]$. The UK regulator has recently recognized that replacement and reinforcement activities should be funded from a single budget [61]. The significance of considering system aspects in replacement planning and vice versa is also illustrated in Table I through the comparison of costs of copper losses and loss-of-lives for $1 \mathrm{~km}$ of $11(6.6) \mathrm{kV}$ cable with the following data: loading $50 \%$; energy price $£ 0.1 / \mathrm{kWh}$; replacement cost (excavate \& lay) $£ 100,000 / \mathrm{km}$; nominal life $40 \mathrm{yr}$; annual maintenance rate $2 \% / \mathrm{yr}$. The ratio of replacement to reinforcement costs is typically 4 5:1 in the UK.

TABLE I-LOSSES VS REPLACEMENT COSTS FOR MV CABLE

\begin{tabular}{|c|c|c|c|c|}
\hline Cable Type & Rating (A) & $\begin{array}{c}\text { Resistance } \\
(\Omega / \mathbf{k m})\end{array}$ & $\begin{array}{l}\text { Cost of } 1 \mathrm{~h} \\
\text { Losses }(\mathfrak{E})\end{array}$ & $\begin{array}{c}\text { Cost of } 1 \mathrm{~h} \\
\text { Life }(\mathfrak{E})\end{array}$ \\
\hline $3 \mathrm{c} 95 \mathrm{Cu}$ & 300 & 0.194 & 0.44 & 0.51 \\
\hline $3 \mathrm{c} 240 \mathrm{Al}$ & 390 & 0.128 & 0.48 & 0.51 \\
\hline $3 \mathrm{c} 300 \mathrm{Cu}$ & 560 & 0.064 & 0.50 & 0.51 \\
\hline
\end{tabular}

Consideration of system aspects in replacement planning was first done for ageing transformers, which are arguably the most important components. Hence, the ageing and replacement of cables and transformers was reviewed and classified into four categories: a) Ageing processes in cable [310] and transformers [11-16]; b) Power system analyses with ageing components [17-24]; c) Replacement of individual/ populations of cable [2, 25-27] and transformers [28]-[31]; and d) Cable and transformer replacement based on power system analyses [32-34].

Accelerated cable ageing using elevated voltages and temperatures is studied in $[3,4,6]$, comparative ageing with and without voltage transients in [5], mechanisms of impulse strength degradation in [7], impact of several operational factors on cable life expectancy in [9] and degradation of the conductor screen in [10]. This group of papers studies the physical characteristics of cable ageing when subjected to different stresses and environmental conditions. The results from test methods $[4,5]$ can be used to develop statistical reliability models of ageing cable, whilst methods $[8,9]$ make use of cable thermal models and can be used for ageing cable reliability models based on their physical properties. Both groups of reliability models can subsequently be incorporated into a probabilistic methodology for replacement planning. Transformer ageing approaches [11-16] can be classified into two groups: a) Analyses based on experimental results [11, 13, 16]; and b) Analyses where impacts of different stress factors are incorporated into a transformer thermal ageing model [12, 14, 15]. Methods from the latter group estimate the transformer life by studying individual transformers and can theoretically be used to predict transformer replacement in future. The main disadvantage is that future uncertainties and interaction among assets are not considered.

On the system level, ageing component models were firstly applied in reliability studies [17-20]. They consider the impact of ageing components on system and nodal reliability indices without analyzing replacement aspects. Recently published papers [21-24] investigate the impact of electric vehicle charging strategies and home energy management systems on distribution transformer ageing. They propose methods for optimal vehicle charging and 'smart' load management so that distribution transformer ageing is minimized. However, control methods are always imposed on end users, 'network models' are simply load balances at the secondary sides of distribution transformers, and replacement is not considered.

Several methods for replacement of individual cables or cable totals without considering the distribution network have been proposed in [25-27]. The life-cycle costing approach in [25] models cable deterioration assuming a linearly varying cable hazard rate over time and investigates different decision options (e.g. test, repair, replace). However, it makes use of many heuristic rules and parameters, and does not consider future uncertainties or network operation. The approach in [26] determines the number of cable replacements required to achieve a specified failure level of the cable population. The model cannot be applied to individual cable sections because it determines the totals of cable replacement. The model and tool from [27] use health indices for transmission cable prioritization and complete a techno-economic study to find the best decisions. However, health indices are calculated from condition data based on online and offline diagnostics which are typically not available in distribution companies. The prioritization of transformers in [28] is based on risk scores calculated from transformer condition indicators and criticality. The robustness of this method can be challenged because it is based on heuristic rules and criticality is a very crude approximation of the network impact. Predictions of the transformer life expectancy based on exponential hazard rate over time [29], a degree of polymerization degradation model [30], and statistical data from a transformer population [31] are used to analyze different replacement strategies. However, there is either no forecast of future operating conditions [30], or modelling is highly simplified [29, 31].

On the other hand, investigation of asset replacement based on whole-system studies is very limited [32-34]. A network reliability simulation methodology that makes use of the exponential hazard rate model was used in [32] to assess the economic benefits of proactive cable replacement. Its main disadvantage is the use of a continuity reliability method [52] that does not consider asset and operation constraints, nor network control actions. The authors of paper [33] have proposed the 'IEC-Arrhenius-Weibull' reliability model for ageing cable to include cable properties and future operating conditions, and used it in a simplified network simulation software to prioritize cable replacement. Finally, prioritization of transformers for replacement based on non-sequential reliability analysis was proposed in [34] in which a single year 
with only load variation is studied. The lack of comprehensive methodologies that can investigate network reinforcement in conjunction with asset replacement under the future significantly different operating conditions is evident.

Integration of new LCTs and application of 'smart' solutions in distribution networks has been more widely investigated [35-42]. One of the most important aspects is the integration of distributed generation (DG) [3-5, 11]. Typical objectives can be to maximize connected DG, to minimize losses, and to improve power flows to meet constraints [35-37, 39, 40, 42, 43]. The approaches make use of deterministic optimization models $[35,37,40]$, or probabilistic methods including different uncertainties [36, 37, 39]. On the other hand, topology configuration and reconfiguration is one of the most important control actions on distribution networks [38, 40, 42-49]. The objective of the former is to minimize losses and/or the cost of reliability during system normal operation [43, 44, 46, 50]. Restoration of disconnected customers with possibly minimal deviation of operational constraints is the primary goal of network reconfiguration in system emergencies [38, 42, 45, 47-49]. However, the authors are not aware of any research that investigates impact of DG integration and/or network reconfiguration on asset ageing and replacement. Besides, real replacement strategies have never been based on the detailed simulation of distribution network operation including available control actions.

This paper investigates distribution cable replacement based on system studies and the use of DG and network reconfiguration to reduce cable ageing and postpone its replacement. A probabilistic approach based on sequential Monte Carlo simulation (SMCS) is developed to find cable ranking lists for their replacement. This was considered the best approach to model various types of uncertainty and chronological phenomena. The proposed methodology makes use of the recently developed 'IEC-Arrhenius-Weibull' model, used to sample up-times of ageing cable [33]. The focal points of the methodology are optimal connection of the prespecified set of new wind units and optimal network reconfiguration whose common objective is to minimize the total cost including cable loss-of-lives. Both models are set within a mixed-integer non-linear programming (MINLP) framework and solved with the aid of commercial routines [63]. Within simulations, several indicators are associated with each cable section to assess its financial impact on the utility: customer interruptions (CIs), customer minutes lost (CMLs), number of failures, changes in the loss-of-life of other cable sections and considered section loss-of-lives.

The main contributions of the paper are:

- A methodology that combines network reinforcement and cable replacement by studying various uncertainties and varying operational conditions in the planning period is developed.

- The proposed methodology is developed for replacement planning of ageing cable. It considers the entire distribution network and is realized within three stages. Compared to the probabilistic simulation methodology [32], the proposed methodology contains many additional features, such as 'IEC-Arrhenius-Weibull' model [33], real-time thermal ratings of assets, wind modelling with a stochastic process, optimal wind integration and network control actions, and novel cable prioritization for replacement. Compared to the authors' previous work [33], additional features include the development of a three-stage SMCS procedure as opposed to two-stage SMCS [33], modelling of two cable thermal models [55, $56]$ in the 'IEC-Arrhenius-Weibull' model, development of optimal wind integration and network reconfiguration models, and a novel cable ranking criterion.

- Reduction in cable ageing and replacement deferral are realized by optimal wind integration and optimal network reconfiguration. These two remedies have never before been applied in asset replacement methodologies.

- The proposed optimization model for wind integration contains two novel features. Firstly, a new term, cost of cable loss-of-lives in the planning period, is developed and added to the objective function. Secondly, network reinforcement and network reconfiguration are included in the model. This approach required the development of a new set of logical constraints, as well as generalization of radiality constraints originally proposed in [46].

- Two network reconfiguration models are developed. The optimal reconfiguration model has the objective function extended with a new term: hourly cost of cable loss-oflives. When convergence of the optimization model is not achieved, a simplified reconfiguration model based on maximum capacity backfeeding paths [36] is used.

- Beside the cable ranking criterion proposed in [33], a novel cable ranking criterion is proposed in this paper. Both criteria are based on the financial impact of individual cable sections on the distribution company in the next price regulation period. Such criteria have never before been used in asset prioritization; the 'closest approach' [32] investigates impact of replacement strategies on system SAIFI and SAIDI.

The methodology is developed for MV distribution networks but is general, and can also be applied to transmission networks. Then, the following features would need to be considered: a) Ageing of transformers and overhead lines is the dominant concern; b) The most important control action is rescheduling of despatchable generation which should take precedence over on-network switching; and c) Large wind generators need to be owned by the transmission company.

\section{Global Formulation of The Methodology}

The proposed methodology consists of three main entities. The first entity is used to determine the ageing and non-ageing cable, since their reliability models are different. Optimal connection of the pre-specified wind units is completed in the second stage, whilst optimal management of the distribution network in the planning period is the scope of the third entity.

A simplified flowchart of the overall methodology is shown in Fig. 1. The first block is a preparatory phase in which hourly simulation of the network historic period, denoted as $\mathrm{SMCS}^{\mathrm{I}}$, is completed with the aim to find parameters of the 
Arrhenius ageing model $[33,51]$ and classify cable as ageing and non-ageing. Analysis of the planning period starts with the second block, in which pre-specified DG units are connected with minimal capital cost for DG connection and network reinforcement. This block is only used before the first simulation run of the planning period, SMCS ${ }^{\mathrm{II}}$, because costs of cable loss-of-lives are not known at this stage. Results from the first two blocks are used to initialize the sequential simulation of the planning period SMCS ${ }^{\mathrm{II}}$ on an hourly basis.

The simulation of the planning period SMCS ${ }^{\mathrm{II}}$ consists of several stages that are described in the next section. The last stage of hourly analysis is network reconfiguration, with the objective to minimize hourly costs of variable losses, cable loss-of-lives and the cost of reliability. One of the simulation stage outputs, the loss-of-lives of all cable sections, is then used to find the improved connection of new DG units by minimizing the connection and reinforcement costs, as well as costs of cable loss-of-lives in the planning period (the feedback loop in Fig.1). Convergence of the iterative process is obtained when there is no difference in DG connections between two consecutive simulation runs in SMCS ${ }^{\mathrm{II}}$. Reliability and cost indicators, ranking lists for cable replacement, and investment and operation costs are calculated at the end of the procedure.

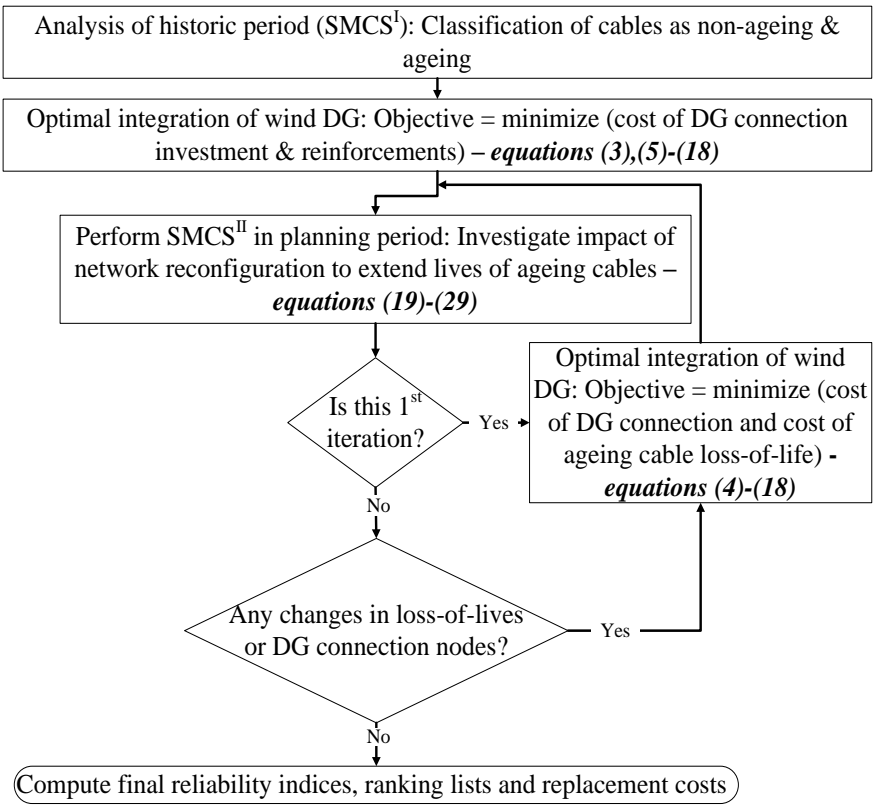

Fig. 1 - Flowchart of the global methodology

\section{DEVELOPED MODELS}

A brief description of the three main blocks from Fig.1 are presented in this section. These are 'simulation of the historic period', 'integration of wind generation' and 'simulation of the planning period'.

\section{A. Simulation of the Historic Period}

Probabilistic simulation of the network operation within the historic period is done with the aid of SMCS ${ }^{\mathrm{I}}$ procedure [52]. The relevant chronological phenomena are load curtailments, wind generations, real-time thermal ratings (RTTRs) and cumulative thermal loss-of-lives. All network components and traditional generation units are at the 'useful life' stage, so that exponentially distributed up- and down-times are applied [52]. Relative hourly profiles are used to determine nodal loads in the studied time step [53]. Load varies in a window around this profile and random sampling is applied to get the nodal relative temporal values. ARMA process is used to sample wind generation as shown in [54], whilst cable RTTRs are found from the IEC cable thermal models [55, 56].

Thermal stress is one of major factors that affects ageing of cable insulation [51]. Cable insulation life $L(\cdot)$ is a function of the conductor temperature and can be defined by the Arrhenius life-stress model [51]:

$$
L\left(\theta_{c}\right)=A \exp \left(\frac{B}{\theta_{c}}\right)
$$

Parameters $A$ and $B$ are empirical constants that are identified using the estimation method based on an iterative procedure and end-of-life statistical data [33]. If parameters $A$ and $B$ are calculated so that unity life corresponds to nominal conductor temperature (i.e. $L\left(363^{\circ} K\right)=1$ ), Arrhenius model (1) can be used to calculate the thermal loss-of-life at variable conductor temperatures using the following relation $[33,51]$ :

$$
L_{T}=\sum_{p=1}^{M} \frac{t_{p}}{L_{p}\left(\theta_{c, p}\right)}+\sum_{q=1}^{N} \frac{t_{q}}{L_{q}\left(\theta_{c, q}\right)}=L_{T}^{\prime}+{L^{\prime \prime}}_{T}
$$

where the first sum $L_{T}^{\prime}$ denotes loss-of-life in the historic period ( $M$ intervals) and second sum $L^{\prime \prime}{ }_{T}$ in the planning period ( $N$ intervals). If loss-of-life $L_{T}$ is divided by the nominal life (say 40 years times 8760 hours), the relative lossof-life is obtained. In the initialization stage, summation over historic intervals (first term in (2)) is calculated and used to classify cable as ageing and non-ageing. An empirical threshold of $>0.875$ has been used to define ageing cable (i.e. 35 years out of 40 years). This classification will be used in the simulation of the planning period - SMCS ${ }^{\mathrm{II}}$.

\section{B. Integration of Wind Generation}

New DG units are connected before network operation is simulated, as shown in Fig. 1. Different approaches are applied for the first and subsequent 'main' SMCS ${ }^{\mathrm{II}}$ runs, because cable thermal loss-of-lives are calculated in the next stage - Fig. 1. Both DG integration models are given below.

\section{a) Objective Functions}

The initial objective (i.e. before the first simulation run SMCS $^{\text {II }}$ - Fig. 1) is minimization of connection costs of new DG units and potential reinforcement costs of the mediumvoltage (MV) network. It was assumed that DG units are owned by the utility, each plant can therefore be built at several locations and each DG location can be connected to the existing network via several new branches. The number of DG units is pre-defined as it was assumed that the utility will make use of their own units only. The investment cost is:

$$
\begin{aligned}
\operatorname{COST}_{I N V}= & \sum_{k \in \Omega_{D G}} \sum_{n_{k} \in \Omega_{D G-\text { nod,k }}} y_{n_{k}} \sum_{n_{k} i \in \Omega_{\text {new }}-b r, n_{k}}\left[\operatorname{cost}_{n_{k} i}^{\text {new }} \cdot \operatorname{cr}_{n_{k} i}^{\text {new }}\right] \\
& +\sum_{i j \in \Omega_{b r}}\left[\operatorname{cost}_{i j}^{\text {rein }} \cdot \operatorname{cr}_{i j}^{r e i n}\right]+\sum_{k \in \Omega_{D G}} \operatorname{cost}_{k}^{D G}
\end{aligned}
$$


The first term in (3) describes costs of new 'DG-branches' required to connect several DG units to the network. The first summation goes over all DG units $k \varepsilon \Omega_{D G}$, the second covers all feasible locations $n_{k} \varepsilon \Omega_{D G \text {-nod, } k}$ for DG unit $k$, whilst the third sum is over all potential 'DG-branches' $n_{k} i \varepsilon \Omega_{\text {new-br,nk }}$ connecting feasible DG location $n_{k}$ and existing node $i$ for each such location $n_{k}$ and each DG unit $k$. The second term in (3) gives investment costs of reinforcing existing branches $i j$. The third term is the cost of committed DG units, which is constant since no new units are procured. In the case where third parties own the DG units, a DG location $n_{k}$ is known, there is no decision variable $y_{n k}$ and the second summation can be omitted.

Following the first simulation run SMCS ${ }^{\mathrm{II}}$, we have used wind-DG units to extend lives of cable sections and defer replacement (Fig. 1). Total cable thermal loss-of-life is defined by (2) in which the second term, $L^{\prime \prime}{ }_{T}$, is calculated within the $\mathrm{SMCS}^{\mathrm{II}}$ procedure. We have used normalized $L^{\prime \prime}{ }_{T} \in\{0-1\}$ as a weight that multiplies replacement cost of cable sections, so that the total cost is:

$$
\begin{aligned}
\operatorname{COST}_{I N V}^{T O T} & =\operatorname{COST}_{I N V}+\sum_{i j \in \Omega_{b r}}\left[\operatorname{cost}_{i j}^{r e i n} \cdot o c_{i j} \cdot L^{\prime \prime} T_{i j}\right] \\
& \approx \operatorname{COST}_{I N V}+\sum_{i j \in \Omega_{b r}}\left[\frac{\operatorname{cost}_{i j}^{r e i n}}{S_{i j}^{r a t}} \cdot S_{i j}(\cdot) \cdot o c_{i j} \cdot L^{\prime \prime}{ }_{T i j}\right]
\end{aligned}
$$

The first equality indicates that cable sections with the highest cost of loss-of-lives will be opened in the optimum solution. However, a cost model often used in marginal network pricing has been applied [57], to minimize the loading of 'expensive' cable sections - second equality in (4). Here, replacement cost is equal to the unit cost in $£$ /MVA multiplied by peak power flow [58], where peak power flow is usually winter peak regime (demand dominated networks) and rarely summer minimum regime (generation dominated networks).

\section{b) Constraints}

Constraints of the wind integration model are given below:

$\left[m_{i} \cdot P_{S_{i}}+P_{D G_{i}}-P_{D_{i}}-\right.$

$\sum_{i j \in \Omega_{b r}} o c_{i j} \cdot P_{i j}(\cdot)-$

$\left.\sum_{k \in \Omega_{D G}} \sum_{n_{k} \in \Omega_{D G-n o d, k}} \sum_{n_{k} i \in \Omega_{n e w-b r, n_{k}}} c r_{n_{k} i}^{n e w} \cdot o c_{n_{k} i} \cdot P_{n_{k} i}(\cdot)\right] \cdot$

$y_{i}=0 \quad \forall i \in \Omega_{\text {nod }}$

$\left[m_{i} \cdot Q_{S_{i}}+Q_{D G_{i}}-Q_{D_{i}}-\right.$

$\sum_{i j \in \Omega_{b r}} o c_{i j}$.

$Q_{i j}(\cdot)-\sum_{k \in \Omega_{D G}} \sum_{n_{k} \in \Omega_{D G-n o d, k}} \sum_{n_{k} i \in \Omega_{n e w-b r, n_{k}}} c r_{n_{k} i}^{n e w} \cdot o c_{n_{k} i} \cdot$

$\left.Q_{n_{k} i}(\cdot)\right] \cdot y_{i}=0 \quad \forall i \in \Omega_{\text {nod }}$

$o c_{i j} \cdot I_{i j}^{2}(\cdot) \leq\left(c e_{i j} \cdot \bar{I}_{l j}^{e x}+c r_{i j}^{r e i n} \cdot{\overline{I_{l j}}}^{\text {rein }}\right)^{2} \quad \forall i j \in \Omega_{b r}$

$c r_{n_{k} i}^{\text {new }} \cdot o c_{n_{k} i} \cdot I_{n_{k} i}^{2}(\cdot) \leq c r_{n_{k} i}^{\text {new }} \cdot\left(\overline{I_{n_{k} l}} \text { new }\right)^{2} \quad \forall n_{k} i$

$\in \Omega_{\text {new }-b r, n_{k}} \forall n_{k} \in \Omega_{D G-n o d, k} \quad \forall k \in \Omega_{D G}$

$$
\begin{gathered}
y_{i} \cdot V_{i}^{\min } \leq\left(y_{i} \cdot V_{i}\right) \leq y_{i} \cdot V_{i}^{\max } \quad \forall i \in \Omega_{\text {nod }} \\
0 \leq P_{D G_{i}} \leq P_{D G_{i}}^{\max } \quad \forall i \in \Omega_{\text {nod }}
\end{gathered}
$$

$$
\sum_{n_{k} \in \Omega_{D G-n o d, k}} y_{n_{k}}=1 \quad \forall k \in \Omega_{D G}
$$

$$
\begin{aligned}
& \sum_{n_{k} \in \Omega_{D G-n o d, k}} \sum_{n_{k} i \in \Omega_{n e w-b r, k}} c r_{n_{k} i}^{n e w}=1 \quad \forall k \in \Omega_{D G} \\
& \left(1-y_{n_{k}}\right) \sum_{n_{k} i \in \Omega_{\text {new-br,k }}} c r_{n_{k} i}^{n e w}=0 \quad \forall n_{k} \in \Omega_{D G-n o d, k} \quad \forall k \\
& \in \Omega_{D G} \\
& \sum_{i j \in \Omega_{b r}} o c_{i j} \cdot f_{i j}+\sum_{n_{k} i \in \Omega_{n e w-b r, k}}^{c e_{i j}+c r_{i j}^{r e i n}=1} c r_{n_{k} i}^{\text {new }} \cdot o c_{n_{k} i} \cdot f_{n_{k} i} \\
& =y_{n_{k}} \quad \forall n_{k} \in \Omega_{D G-n o d, k} \quad \forall k \in \Omega_{D G} \\
& \sum_{i j \in \Omega_{b r}} o c_{i j} \cdot f_{i j}+\sum_{n_{k} i \in \Omega_{n e w-b r, k}} c r_{n_{k} i}^{\text {ew }} \cdot o c_{n_{k} i} \cdot f_{n_{k} i}=0 \\
& \left|f_{n_{k} i}\right| \leq N_{D G} \cdot c r_{n_{k} i}^{n e w} \cdot o c_{n_{k} i} \quad \forall n_{k} i \in \Omega_{n e w-b r, n_{k}} \quad \forall n_{k} \\
& \in \Omega_{D G-\text { nod,k }} \forall k \in \Omega_{D G} \\
& \left|f_{i j}\right| \leq N_{D G} \cdot o c_{i j} \quad \forall i j \in \Omega_{b r} \\
& \sum_{i j \in \Omega_{b r}} o c_{i j}+\sum_{k \in \Omega_{D G}} \sum_{n_{k} \in \Omega_{D G-n o d, k}} \sum_{n_{k} i \in \Omega_{n e w-b r, n_{k}}} c r_{n_{k} i}^{n e w} \cdot o c_{n_{k} i} \\
& =N_{b}+N_{D G}-\sum_{\Omega_{\text {sub }}} m_{i}
\end{aligned}
$$

Active and reactive power balances at existing and new nodes are specified by equations (5a) and (5b), respectively. The first term, expressed via binary variable $m_{i}$, models supplies from (a) primary substation(s) $\left(m_{i}=1\right.$ if they are used, $m_{i}=0$ otherwise). The first summation specifies power flows in existing branches where the branch status (open/close) is accounted for, whilst the second summation is for 'DGbranches' in which both the branch existence (constructed or not) and status are taken into account. All power balances are multiplied by 'locational' decision variable $y_{i}=y_{n_{k}}$ in the case of all new nodes candidates for DG connection, whilst $y_{i}=1$ for all existing nodes; the latter is used to simplify presentation. Active $P_{i j}(\cdot)$ and reactive power flows $Q_{i j}(\cdot)$ in branches $i j$ are functions of terminal voltages and angles [46], which are model unknowns.

'Standard' thermal and voltage constraints are specified by inequalities (6), (7) and (8). Current flow $I_{i j}(\cdot)$ in all closed existing branches $i j$ (i.e. $o c_{i j}=1$ ) needs to be less or equal to the existing nominal rating if $c e_{i j}=1$, or the rating of the branch reinforcement if $c r_{i j}^{\text {rein }}=1$, as shown by $(6) ; I_{i j}(\cdot)$ is a function of terminal voltages and angles [46]. A 'similar' constraint needs to be set for all 'DG-branches' candidates for connection of new DG units to the network; note the existence of binary construction variable $c n_{n_{k} i}^{n e w}$ on both sides of relations (7), because no additional constraint was set on the link between $c r_{n_{k} i}^{n e w}$ and $o c_{n_{k} i}$ (i.e. where $c r_{n_{k} i}^{n e w}=0=>o c_{n_{k} i}=0$ ). Locational decision variable $y_{i}=y_{n_{k}}$ is used for voltage constraints at all new nodes (8), whilst $y_{i}=1$ in the case of all existing nodes. Capacity constraints of DG units are defined by relations (9), and they are binding only in cases when the sampled wind speed is above the DG maximum wind speed.

A set of logical constraints on binary construction and location variables is specified via relations (10) to (13). Condition (10) defines that each DG unit can be located at only one site $n_{k}$, whilst expression (12) ensures that there are no new circuits constructed in branches towards non-used DG sites (i.e. where $y_{n_{k}}=0$ ). Constraints (11) specify the number 
of new circuits connecting each new DG plant $k$ to the existing network. Equation (11) implies 'non-firm' connection (i.e. DG is teed-off), whilst 'firm' connection (i.e. DG is looped in) is modelled by setting the right-hand side to 2 . Finally, equation (13) specifies that either the existing circuit $\left(c e_{i j}=1\right)$ or the new one $\left(c_{i j}^{\text {rein }}=1\right)$ is used in existing branch $i j$.

Integration of DG units into a radially operated network creates a possibility that the optimal solution contains isolated islands in which all loads are supplied by DG units. This problem was overcome in [46] by introducing the concept of fictitious power flows. Fictitious loads are connected at nodes with DG units and they create fictitious power flows that prohibit network islanding. The original approach [46] was modified to include new DG nodes candidates for DG connection, as defined by relations (14) to (17). Fictitious power balances at each new node $n_{k}$ and existing nodes are defined by equalities (14) and (15), respectively. All fictitious power flows in new 'DG-branches' and existing branches are limited, as shown in (16) and (17), respectively. These flows are forced to zero for open or non-constructed branches. The last constraint (18) defines radial operation of the network for the general case when several substations supply the network.

\section{Simulation of the Planning Period}

The section contains three entities: a) Simulation procedure; b) Optimal network reconfiguration and c) Cable ranking lists.

\section{a) Simulation Procedure}

A simplified flowchart of the 'main' SMCS ${ }^{\text {II }}$ simulation procedure is shown in Fig. 2. Simulation is done over the next regulatory period whose length is between 5 and 8 years; it covers $5(8) * 8760$ hourly intervals and is repeated until the coefficient of variation of the expected energy not served (EENS) is less than the prescribed tolerance (5\%).

Following the data input and SMCS ${ }^{\mathrm{II}}$ initialization, loadflow analysis of the current hour is done. To this end, loads are sampled from a window around the profile and wind generations are determined from the ARMA processes [54]. Where appropriate, statuses of network components are set/changed using the results from the previous samplings and/or possible resupply from the back-feeding feeders. The up-and down-times of non-ageing components are sampled from the exponential model [52], whilst 'IEC-ArrheniusWeibull' model [33] is used to sample up-times of ageing cable that have just been repaired. This model describes the wear-out stage with the aid of Weibull probability distribution in which scale parameter is replaced with $L\left(\theta_{c}\right)$ from the Arrhenius model (1), and conductor temperature $\theta_{c}(I(t))$ is found from one of two IEC cable thermal models $[55,56]$. In this way, cumulative failure function $F\left(\theta_{c}(I(t))\right.$ is used to sample up-times of ageing cable [33].

Network reconfiguration (denoted as 'restoration scheme' in Fig 2) is done next. Its simplest version, based on maximum capacity backfeeding paths [36], is only used when the proposed optimization model does not converge and for the comparison between the proposed methodology and the 'standard' network operation during emergencies. The proposed optimal network reconfiguration, whose objective is minimization of hourly cost of losses, cable loss-of-lives and curtailed demand, is run in each hour of the simulation period. Reliability indices SAIFI (CIs), SAIDI (CMLs) and EENS (if any), as well as thermal loss-of-lives are updated. Reliability indices are allocated to the cable section which has caused supply disruption. Increments in loss-of-lives of other cable sections are found and allocated to the faulty cable section; they are calculated from the post-fault and pre-fault currents.

Following the SMCS ${ }^{\mathrm{II}}$ convergence, final reliability indices, cost indicators and cable ranking lists are determined.

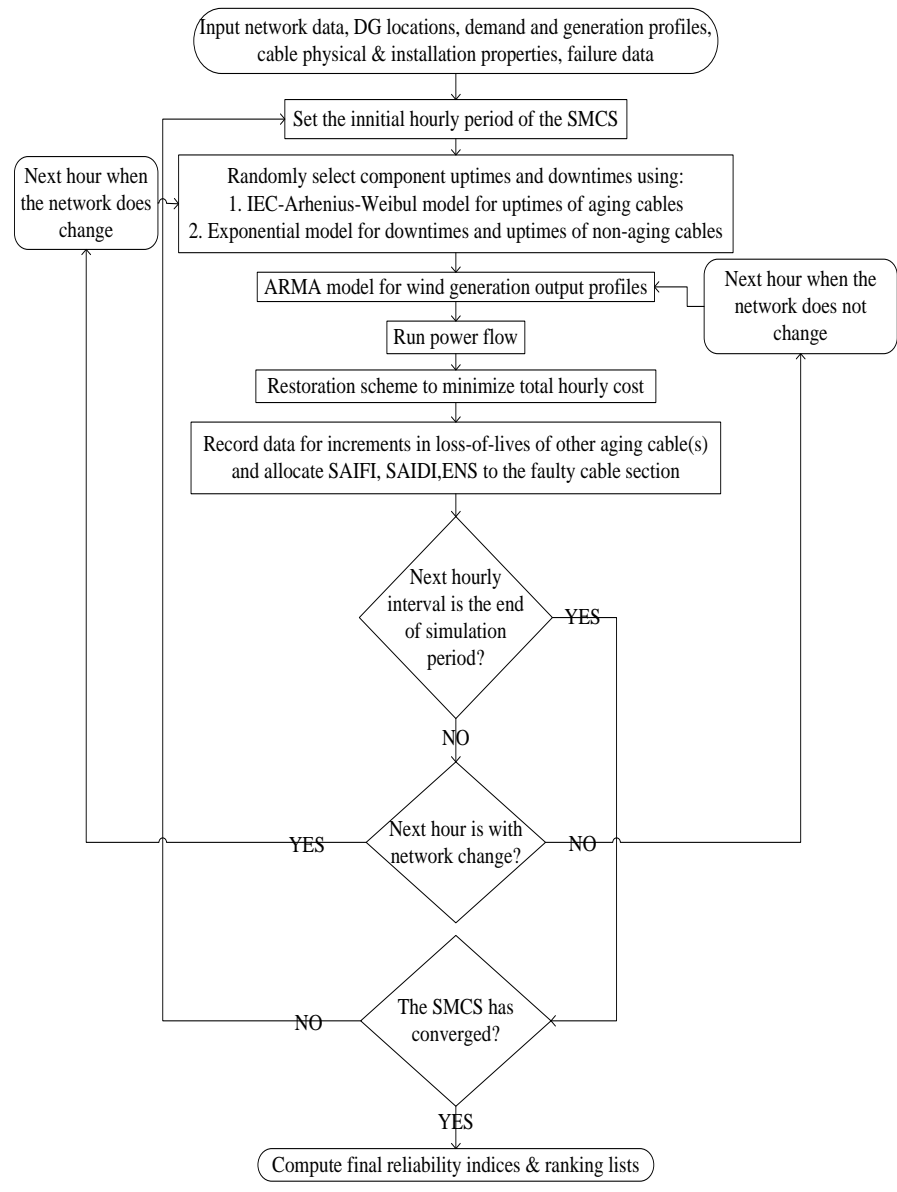

Fig. 2 - Flow chart of the 'main' SMCS ${ }^{\text {II }}$ procedure

b) Optimal Network Reconfiguration

The objective of the optimal network reconfiguration is to supply as many customers as possible at the minimum cost; the latter is hourly cost of cable loss-of-lives, variable losses and non-delivered energy:

$$
\begin{gathered}
\operatorname{CosT}(t)=\sum_{i j \in \Omega_{b r}} o c_{i j} \cdot\left[\operatorname{cost}_{L o L}\left(I_{i j}(t)\right)+\operatorname{cost}_{E E} \cdot R_{i j}\right. \\
\left.\cdot I_{i j}(\cdot)^{2}\right]+\sum_{i \in \Omega_{\text {nod }}} \operatorname{cost}_{E N S} \cdot L C_{i}
\end{gathered}
$$

where the hourly cost of cable loss-of-life section $i j$ is:

$$
\begin{array}{r}
\operatorname{cost}_{\text {LoL }}\left(I_{i j}(t)\right)=\frac{\operatorname{cost}_{i j}^{\text {rein }}}{8760 \cdot T_{\text {life }}} \cdot \Delta L_{T}\left(\theta_{c}\left(I_{i j}(t)\right)\right) \\
\approx \frac{\operatorname{cost}_{i j}^{\text {rein }}}{8760 \cdot T_{\text {life }}} \cdot\left[1+\xi \cdot\left(I_{i j}(t)-I_{i j}^{\text {rat }}\right)\right]
\end{array}
$$


with the assumed cable design life $T_{\text {life }}=40 \mathrm{yr}$. The hourly lossof-life $\Delta L_{T}(\cdot)$ is calculated from Arrhenius model (1) in which conductor temperature $\theta_{c}(I(t))$ is replaced from one of the two IEC thermal models $[55,56]$. A linear approximation around the nominal temperature-current can be used to speed-up computation, as shown by second equality in (20).

Model constraints are simpler than for the wind integration, because there are neither locational nor investment binary variables. The only decision variables are operational variables $o c_{i j}$. Assuming that sets of existing nodes and branches now include the known DG locations and connecting 'DG-branches', and branch thermal limits are modified according to the solution of model (4) to (18), the constraints are:

$$
\begin{gathered}
m_{i} \cdot P_{S_{i}}+P_{D G_{i}}+L C_{i}-P_{D_{i}}-\sum_{i j \in \Omega_{b r}} o c_{i j} \cdot P_{i j}(\cdot)=0 \forall i \in \Omega_{n o d} \\
m_{i} \cdot Q_{S_{i}}+Q_{D G_{i}}+L C_{i} \cdot \tan \varphi_{i}-Q_{D_{i}}-\sum_{i j \in \Omega_{b r}} o c_{i j} \cdot Q_{i j}(\cdot) \\
=0 \quad \forall i \in \Omega_{n o d} \\
o c_{i j} \cdot I_{i j}^{2}(\cdot) \leq\left(\overline{I_{l j}} e x\right)^{2} \quad \forall i j \in \Omega_{b r} \\
V_{i}^{\text {min }} \leq V_{i} \leq V_{i}^{\max } \quad \forall i \in \Omega_{n o d} \\
0 \leq L C_{i} \leq P_{D_{i}} \quad \forall i \in \Omega_{n o d} \\
0 \leq P_{D G_{i}} \leq P_{D G_{i}}^{\max } \quad \forall i \in \Omega_{n o d} \\
\sum_{i j \in \Omega_{b r}} o c_{i j} \cdot f_{i j}=K_{i} \quad \forall i \in \Omega_{n o d} \\
\left|f_{i j}\right| \leq N_{D G} \cdot o c_{i j} \quad \forall i j \in \Omega_{b r} \\
\sum_{i j \in \Omega_{b r}} o c_{i j}=N_{b}+N_{D G}-\sum_{\Omega_{s u b}} m_{i}
\end{gathered}
$$

Nodal active and reactive power balances (21) and (22) contain load curtailments, branch thermal limits are defined by (23), nodal voltage limits by (24), load curtailment limits by (25) and generation capacities by (26). Relations (27) and (28) specify constraints on fictitious power flows needed when DG units are connected, whilst radiality constraint is set by (29).

\section{c) Cable Ranking Lists}

Cable prioritization for replacement can be based on direct financial implications in the forthcoming regulatory period. The financial exposure consists of the revenue lost under the quality-of-supply (QoS) incentives on CIs and CMLs, as well as the costs of repairing faulty cables [33]:

$$
\operatorname{COST}_{1}=\Delta C I * C I_{I n c}+\Delta C M L * C M L_{I n c}+N O_{\text {fail }} * C_{\text {fail }}
$$

where $\triangle C I$ and $\triangle C M L$ are customer interruptions (SAIFI) and customer-minutes-lost (SAIDI) caused by the considered cable section in the regulatory period. We have used QoS incentive rates $C I_{I n c}=17.85 £ / c u s t$ and $C M L_{I n c}=5.84 £ / \mathrm{min}$, as well as $C_{\text {fail }}=£ 10,000$ in our studies [59]; these values are company specific and the first two are set by the UK regulator.

It is proposed in this paper to extend ranking criterion (30) with an 'indirect cost term' that represents impact of the considered cable section (i.e. its fault) on all other cables in terms of additional ageing caused by increased currents:

$$
\begin{aligned}
\operatorname{COST}_{2}= & \operatorname{COST}_{1} \\
& +\sum_{t} \sum_{i j \in \Omega_{b r}}\left[\operatorname{cost}_{L o L}\left(I_{i j}^{p o s t}(t)\right)-\operatorname{cost}_{L o L}\left(I_{i j}^{p r e}(t)\right)\right]
\end{aligned}
$$

where summation goes over all hours $t$ in the planning period and branches ij $\epsilon \Omega_{b r}$ other than the considered one. The incremental cost of cable loss-of-life can be calculated from the post-fault and pre-fault currents using model (20). Finally, cable sections can also be ranked using the loss-of-life criterion (2).

\section{TEST NETWORKS AND OTHER DATA}

Three test networks and other data are described below.

\section{A. IEEE 33-Node Test Network}

A 33-node, $22 \mathrm{kV}$ medium voltage radially operated network, consisting of 32 underground cable sections and 5 tie-lines, was used as the first test system [44]; the network diagram is shown in Fig. 3. The total peak demand in the base year was $3.715 \mathrm{MW}$ and 2.3MVar and these values were used to deduce corresponding peak demands for both the historic and planning periods. The reference hourly load profile within each year was obtained from the IEEE RTS-96 chronological load profile [53]. The cable sections are labelled as L1, L2,.., L37 and it was assumed that each section is $0.5 \mathrm{~km}$ in length, which gives feeder main length of $8.5 \mathrm{~km}$. The assumption was based on the classification of UK urban MV circuits into categories $l<4 \mathrm{~km}, 4 \mathrm{~km}<l<8 \mathrm{~km}$ and $l>8 \mathrm{~km}$ which is being used for quality-of-supply incentives [62]. All loads are denoted as $(\mathrm{kW}, \mathrm{kVAr})$ quantities next to each node and tie-lines are marked with dashed lines.

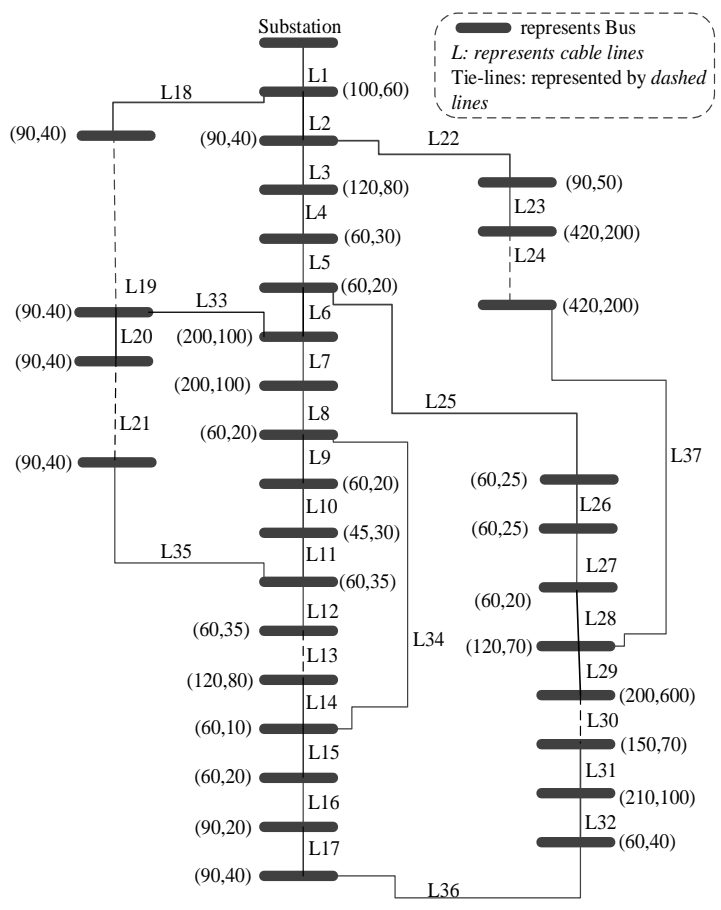

Fig. 3 - IEEE 33-node test network [44] 


\section{B. IEEE 69-Node Test Network}

The second test system is the 69 -node $22 \mathrm{kV}$ radially operated network given in [44]. The peak demand was 3.8MW and 2.62MVar in the base year. The load profile was again adapted from [53]. It was assumed that each section is $0.5 \mathrm{~km}$ in length, so that the longest feeder main was $13.5 \mathrm{~km}$ in length.

\section{IEEE 119-Node Test Network}

The final test system is the 119-node distribution network given in [60]. The peak demand was 6.81MW and 5.11 MVar. The load profile was selected in the same way as above. If it is assumed that each section is $0.5 \mathrm{~km}$ in length, the longest feeder main is around $10 \mathrm{~km}$ in length.

\section{Other Data}

Cable data, required for the IEC thermal model [55], Arrhenius and RTTR modelling, are presented in [33]. Failure and repair rates and restoration times were obtained from [53]. Assuming cable excavate and lay policy, reinforcement costs were set to $£ 50,000 / \mathrm{km}$ for all cable sizes because of very small number of new standard sizes used in companies and very small impact on specific costs $[61,62]$. An uplift of $\sim 40 \%$ (i.e. $£ 70,000 / \mathrm{km}$ ) is used for 'DG branches' to include terminal costs at both ends. The total numbers of connected customers were 1600,3400 and 5900 for the 33-bus, 69-bus and 119-bus systems, respectively.

\section{Simulation Results AND Discussions}

The objective of the study is to find optimal cable replacement programme for the next 5-year regulatory period. A MATLAB software package was developed using AIMMS solver for MINLP optimization [63]. Typical CPU times obtained on a $3.6 \mathrm{GHz}$ quad core, 64-bit system are shown in Table II, where SMCS denotes all Monte Carlo stages other than network reconfiguration. Initialization of the wind integration model (4)-(18) was done using a simplified optimization model based on network flows - first Kirchhoff's law, and no convergence problems were experienced. On the other hand, network reconfiguration model (19)-(29) is solved in each hour of the planning period until convergence of the SMCS $^{\text {II }}$ is reached. To provide a converged solution even when optimal network reconfiguration diverges, the program switches to simple network restoration based on maximum capacity backfeeding paths. We have experienced such situation only in few hours within the whole planning period on the 119-bus test system.

TABLE II - CPU TIME AND SIMULATION DURATION FOR 3 TEST SYSTEMS

\begin{tabular}{|c|c|c|c|c|}
\hline \multicolumn{5}{|c|}{ CPU time (secs) } \\
\hline Test System & DG connection & $\begin{array}{l}\text { Network reconfiguration } \\
(\mathrm{NR})\end{array}$ & SMCS & Total \\
\hline 33 bus & 3741.90 & 22428.71 & 6032.17 & 32202.8 \\
\hline 69 bus & 6244.46 & 33615.64 & 7534.73 & 47394.8 \\
\hline 119 bus & 11607.60 & 50681.21 & 16188.15 & 78477.0 \\
\hline
\end{tabular}

Simulation results are shown in Tables III to VII. Table III presents results of the optimal connection of wind-DG units for the three network management strategies. System wide reliability indices along with sensitivity studies on the degree of ageing are given in Table IV for two proposed strategies. Table V shows a comparison between the three types of 'operational' costs within the planning period: cost of cable loss-of-lives, cost of copper losses and curtailed energy costs. Ranking of cable sections using the thermal loss-of-live criterion is shown in Table VI, whilst Table VII provides cable ranking based on the direct financial exposure (30) and 'total exposure' (31).

Table III shows that two wind-DG units were connected in the 33-node (marked as A-33-0.6MVA and B-33-0.8MVA) and 69-node test networks (marked as A-69-0.4MVA and B69 - 1MVA), whilst three DG units, denoted as A-119 1MVA, B-119 - 0.5MVA and C-119 - 1MVA, were studied in the case of the 119-node test system. Sizes of DG units were selected so that the total DG nominal rating is $25 \%-30 \%$ of the peak load in each system. Potential locations for DG connection (i.e. existing node numbers) are presented in the second column; the choice was based on the proximity to the envisaged DG locations. Three strategies were studied for each network: a) Conventional DG connection (objective function (3)) with 'simple' network reconfiguration (NR) in case of faults; b) Proposed approach for DG connection (objective function (4)) with 'simple' NR in case of faults; and c) Proposed approach for DG connection (objective function (4)) with the proposed optimal network reconfiguration in all hours of the simulation period.

TABLE III - DG CONNECTION, REINFORCEMENT AND INVESTMENT COSTS FOR THREE STRATEGIES

\begin{tabular}{|c|c|c|c|c|c|c|c|c|c|}
\hline \multicolumn{10}{|c|}{ Optimization programs results } \\
\hline 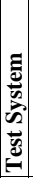 & $\begin{array}{c}\text { New DG } \\
\text { Units }\end{array}$ & $\begin{array}{c}\text { Potential } \\
\text { DG } \\
\text { nodes } \\
\text { (bus \#) }\end{array}$ & \begin{tabular}{|c|} 
Applied DG \\
integration technique \\
and Network \\
Reconfiguration \\
\end{tabular} & 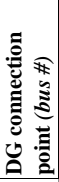 & 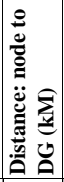 & 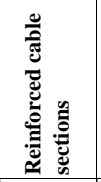 & 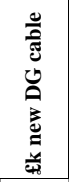 & 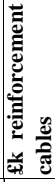 & 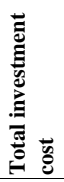 \\
\hline & \multirow{3}{*}{$\begin{array}{l}\text { A-33 } \\
0.6 \mathrm{MVA})\end{array}$} & \multirow{3}{*}{$\begin{array}{c}2,3,4,5 \\
6\end{array}$} & \multirow{2}{*}{$\begin{array}{c}\text { Coventional (eq. 3, } 5 \text { - } \\
18)\end{array}$} & 5 & 1 & \multirow{2}{*}{$5,7,8,26$} & \multirow{2}{*}{$£ 80.5$} & \multirow{2}{*}{$£ 100$} & \multirow{2}{*}{$£ 180.5$} \\
\hline \multirow{5}{*}{$\stackrel{2}{e}$} & & & & 26 & 0.15 & & & & \\
\hline & & & \multirow{2}{*}{$\begin{array}{c}\text { New approach (eq. } 4 \text { - } \\
18) \\
\end{array}$} & 5 & 1 & \multirow{2}{*}{$2,3,26$} & \multirow{2}{*}{$£ 87.5$} & \multirow{2}{*}{$£ 75$} & \multirow{2}{*}{$£ 162.5$} \\
\hline & \multirow{3}{*}{$\begin{array}{c}\text { B-33 } \\
(0.8 \mathrm{MVA})\end{array}$} & \multirow{3}{*}{$25,26,27$} & & 25 & 0.25 & & & & \\
\hline & & & \multirow{2}{*}{$\begin{array}{c}\text { New approach with } \\
\text { optimal NR }(\text { eq. } 4-29)\end{array}$} & 5 & 1 & \multirow{2}{*}{2,26} & \multirow{2}{*}{$£ 87.5$} & \multirow{2}{*}{$£ 50$} & \multirow{2}{*}{$£ 137.5$} \\
\hline & & & & 25 & 0.25 & & & & \\
\hline \multirow{6}{*}{$\frac{a}{3}$} & \multirow{3}{*}{$\begin{array}{c}\text { A-69 } \\
(0.4 \mathrm{MVA})\end{array}$} & \multirow{3}{*}{$\begin{array}{l}39,40 \\
51,52\end{array}$} & Coventional (eq. 3, 5 - & 52 & 0.5 & \multirow{2}{*}{$2,3,48,49$} & \multirow{2}{*}{$£ 70.0$} & \multirow{2}{*}{$£ 100$} & \multirow{2}{*}{$£ 170.0$} \\
\hline & & & 18) & 50 & 0.5 & & & & \\
\hline & & & \multirow{2}{*}{$\begin{array}{c}\text { New approach (eq. } 4 \text { - } \\
18)\end{array}$} & 50 & 0.5 & \multirow{2}{*}{$5,6,40$} & \multirow{2}{*}{$£ 87.5$} & $£ 75$ & $£ 16$ \\
\hline & & & & 39 & 0.75 & & & & 2102.0 \\
\hline & $(1$. & $\begin{array}{c}40,47, \\
50\end{array}$ & New approach with & 50 & 0.5 & 6 & 875 & $f 50$ & fl \\
\hline & & & optimal NR $(\epsilon$ & 40 & 0.75 & 5,0 & $\pm 8 / .5$ & \pm 50 & \pm 137.5 \\
\hline & & & & 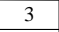 & 0.5 & $1,2,3,9$ & & & \\
\hline & $(1.0$ & $2,3,10$ & $18)$ & 108 & 1.5 & 108,110 & $£ 210.0$ & $£ 175$ & $£ 385.0$ \\
\hline & & & & 63 & 1 & 62 & & & \\
\hline & & 107 & New ap & 2 & 1 & 3, & & & \\
\hline $\overrightarrow{2}$ & (0.5MVA) & 109 & Trew at & 63 & 1 & 63,108 , & $£ 245.0$ & $£ 125$ & $£ 370.0$ \\
\hline I & & & & 108 & 1.5 & 110 & & & \\
\hline & & & New & 3 & 0.5 & & & & \\
\hline & (1.0MVA) & $\begin{array}{l}05,04, \\
65\end{array}$ & optimal NR (eq. 4 - 29 & 108 & 1.5 & & $£ 245.0$ & $£ 100$ & $£ 345.0$ \\
\hline & & & & 64 & 1.5 & & & & \\
\hline
\end{tabular}

It can be seen from Table III that the optimal point of connection of DG units can be dependent on the applied optimization objective. This was obtained for all studied networks, but in general, it is dependent on the input data, particularly lengths of 'DG branches'. The conventional minimum cost approach (model (3), (5)-(18)) usually connects new DG centers via shortest branches, particularly when voltage and thermal constraints are not an issue during 
summer minimum periods. Hence, the DG connection costs can be lower in such cases. On the other hand, when the cost of cable ageing is considered, the optimal DG connection plan can include longer (new) cable sections that will relieve loading of some existing ageing cable sections. The required network reinforcements are also different for the three strategies in all test networks studied. The minimal amount of reinforcement was in all cases obtained when a combination of the new connection approach with the proposed optimal NR was applied. A similar conclusion can be drawn for the total investment costs.

Table IV presents a comparative analysis of the system reliability indices for the two proposed approaches. All results are also given in per unit values, where the reference case in both cases is non-ageing SMCS with Weibull shape parameter $\beta=1$ for conventional approach (not repeated in Table IV). The results show that the new approach with the proposed optimal NR (second part of Table IV) provides the highest reliability and consequently asset preservation and reduced ageing. Absolute reliability indices are worse - higher for the larger networks, whilst per unit values do not exhibit such a trend. Table IV also shows sensitivity of SAIDI and SAIFI indices for several Weibull shape parameter $\beta$ values which reflect intensity of cable ageing. The indices increase quite rapidly (particularly SAIDI) when $\beta$ increases. Practical choice of $\beta$ should be based on comparison with real-life data on historic performance within a company.

\begin{tabular}{|c|c|c|c|c|c|c|c|c|c|c|c|c|}
\hline \multicolumn{13}{|c|}{ Impact indices - new approach (eq. (4)-(18)) } \\
\hline \multirow{2}{*}{\multicolumn{4}{|c|}{ SAIDI (hours / cust. 5yr) }} & \multirow{2}{*}{\multicolumn{5}{|c|}{$\begin{array}{l}69 \text { bus test svstem } \\
\text { SAIDI (hours / cust. 5yr) }\end{array}$}} & \multirow{2}{*}{\multicolumn{4}{|c|}{$\frac{119 \text { bus test svstem }}{A I D I \text { (hours / cust. } 5 y}$}} \\
\hline & & & & & & & & & & & & \\
\hline \multirow[t]{3}{*}{ (ק) } & 1.05 & 1.1 & 1.2 & (3) & 1 & 1.05 & 1.1 & 1.2 & 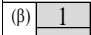 & 1.05 & 1.1 & 1.2 \\
\hline & 0.361 & 0.799 & 2.153 & & 1.163 & 2.3252 & 6.634 & 40.349 & 4.374 & 6.920 & 18.185 & 111.173 \\
\hline & $(24 \mathrm{pu})$ & $(53 \mathrm{pu})$ & $(143 \mathrm{pu})$ & & $(1 \mathrm{pu})$ & $(2 \mathrm{pu})$ & (5.7pu) & (34.7pu) & (1pu) & $(1.6 \mathrm{pu})$ & 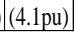 & (pa) \\
\hline \multicolumn{4}{|c|}{ SAIFI (interruptions / cust. } & \multicolumn{5}{|c|}{ SAIFI (interruptions / cust. 5yr) } & \multicolumn{4}{|c|}{ SAIFI (interruptions / cust. 5yr) } \\
\hline (ק) 1 & 1.05 & 1.1 & 1.2 & \multirow{3}{*}{ (b) } & 1 & 1.05 & 1.1 & 1.2 & \multirow{5}{*}{\multicolumn{2}{|c|}{\begin{tabular}{|l|c|c|}
$(\beta)$ & 1 & 1.05 \\
$\begin{array}{l}0.423 \\
(1 \mathrm{pu})\end{array}$ & $\begin{array}{l}0.679 \\
(1.6 \mathrm{pu}\end{array}$ \\
(eq. (4) - (29)) & $\mathbf{1 1 9}$ bus t \\
\multicolumn{10}{|c|}{}
\end{tabular}}} & 1.1 & 1.2 \\
\hline 0.003 & 0.045 & 0.101 & 0.220 & & \begin{tabular}{|l|}
0.126 \\
\end{tabular} & 0.225 & 0.665 & 4.0 & & & 1.795 & 10.970 \\
\hline$(1 \mathrm{pu})$ & $(15 \mathrm{pu}$ & $(33 \mathrm{pu})$ & (73pu) & & (1pu) & $(1.8 \mathrm{pu})$ & $(5.3 \mathrm{p}$ & $(32 \mathrm{pu})$ & & & & $(26 \mathrm{pl}$ \\
\hline \multicolumn{11}{|c|}{ Impact indices - new approach with optimal NR (eq. (4) - (29)) } & & \\
\hline \multicolumn{4}{|c|}{33 bus test system } & \multicolumn{5}{|c|}{69 bus test system } & & & est systen & \\
\hline \multicolumn{4}{|c|}{ SAIDI (hours / cust. 5yr) } & \multicolumn{5}{|c|}{ SAIDI (hours / cust. 5yr) } & \multicolumn{4}{|c|}{ SAIDI (hours / cust. 5yr) } \\
\hline \multirow[t]{3}{*}{ (ß) } & 1.05 & 1.1 & 1.2 & \multirow{3}{*}{\multicolumn{2}{|c|}{ (B) }} & \begin{tabular}{|l|}
1.05 \\
\end{tabular} & 1.1 & 1.2 & \multirow[t]{3}{*}{ (B) } & 1.05 & 1.1 & 1.2 \\
\hline & 0.311 & 0.699 & 1.99 & & & 2.052 & 5.924 & 39.146 & & 6.660 & 16.984 & 99.981 \\
\hline & $(21 \mathrm{pu})$ & $(47 \mathrm{pu})$ & $(132 \mathrm{pu})$ & & & $(1.8 \mathrm{pu})$ & (5.1pu) & $(33.7 \mathrm{pu})$ & & (1.5pu) & $(3.9 \mathrm{pu})$ & $(22.8 \mathrm{pu})$ \\
\hline \multicolumn{4}{|c|}{ SAIFI (interruptions / cust. } & \multicolumn{5}{|c|}{ SAIFI (interruptions / cust. 5yr) } & \multicolumn{4}{|c|}{ SAIFI (interruptions / cust. 5yr) } \\
\hline \multirow[t]{2}{*}{ (ß) } & 1.05 & 1.1 & 1.2 & \multirow{2}{*}{\multicolumn{2}{|c|}{ (ß) }} & 1.05 & 1.1 & 1.2 & \multirow[t]{2}{*}{ (ק) } & 1.05 & 1.1 & 1.2 \\
\hline & $\begin{array}{c}0.04 \\
(13 \mathrm{pu})\end{array}$ & $\begin{array}{l}0.092 \\
30 \mathrm{pu})\end{array}$ & \begin{tabular}{|c}
0.190 \\
$(63 \mathrm{pu})$
\end{tabular} & & & $\begin{array}{c}0.20 \\
(1.6 \mathrm{pu})\end{array}$ & 0.612 & 3.851 & & $\begin{array}{l}0.641 \\
(1.5 \mathrm{pu})\end{array}$ & 1.552 & 9.844 \\
\hline
\end{tabular}

Table V shows the total 'operation' costs (19) in the planning period for the 'base case' with no DG connected and the two developed strategies; they are calculated using the cost figures from Table I and $\operatorname{cost}_{E N S}=15 £ / \mathrm{kWh}$ [64]. 69-node test network has much fewer ageing cable sections and the proportion of loss-of-life costs is smaller. Other than that, the overall pattern of results is 'similar' for the three test networks. It is interesting to compare the total operational cost when DG units are not connected and the new approach whereby simple network reconfiguration in emergencies is used. The integration of the DG units contributes towards reduction of the operational costs, as shown in the first section of Table V. Appreciable savings in 'operation' costs are obtained by applying the proposed optimal NR in each hour as opposed to the simplified network restoration approach in emergencies. It is evident that the optimal network reconfiguration in all hours reduces total operation costs including cost of losses and cable loss-of-lives as well. The latter benefit indicates the possibility to defer asset replacement by applying the optimal NR.

TABLE V - TOTAL OPERATION COSTS FOR ‘BASE CASE' AND TWO STRATEGIES

\begin{tabular}{|c|c|c|c|c|}
\hline \multirow{2}{*}{$\begin{array}{c}\text { Applied DG integration } \\
\text { technique and Network }\end{array}$} & \multirow{2}{*}{ Test System } & \multicolumn{3}{|c|}{ Costs (£) } \\
\cline { 3 - 5 } & 33 bus & $£$ Loss of life & Copper losses & load curtailment \\
\hline \multirow{3}{*}{ No DG } & 69 bus & $£ 4,432.84$ & $£ 7,650.46$ & $£ 29,8752.12$ \\
\cline { 2 - 5 } & 119 bus & $£ 32,549.39$ & $£ 34,443.80$ & $£ 22,700.92$ \\
\hline \multirow{3}{*}{ New approach } & 33 bus & $£ 5,436.99$ & $£ 5,753.42$ & $£ 28,232.13$ \\
\cline { 2 - 5 } & 69 bus & $£ 2,599.48$ & $£ 3,005.34$ & $£ 20,680.27$ \\
\cline { 2 - 5 } & 119 bus & $£ 31,383.42$ & $£ 33,209.96$ & $£ 40,627.86$ \\
\hline \hline \multirow{3}{*}{ New approach with optimal NR } & 33 bus & $£ 4,369.35$ & $£ 4,623.65$ & $£ 27,150.30$ \\
\cline { 2 - 5 } & 69 bus & $£ 2,160.68$ & $£ 2,100.78$ & $£ 19,232.03$ \\
\cline { 2 - 5 } & 119 bus & $£ 30,760.37$ & $£ 32,109.10$ & $£ 38,347.10$ \\
\hline
\end{tabular}

Ranking of cable sections shown in Table VI is based on the historic cable thermal loss-of-lives. Additional loss-of-lives in the planning period are also presented for the three network management strategies. The conventional DG connection combined with 'simple' network restoration gives additional loss-of-lives in descending order which is in line with the historic ranking. The proposed two strategies give reduced additional loss-of-lives for all tested networks when compared to the conventional case. It can also be noticed that there is a perturbation in the cable ranking order relative to the historic and 'conventional' ranking. However, the same cable sections were in the top part of the list.

TABLE VI - CABLE RANKING BASED ON THERMAL LOSS-OF-LIFE

\begin{tabular}{|c|c|c|c|c|c|c|c|c|}
\hline \multirow{2}{*}{ 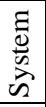 } & \multirow[b]{2}{*}{ Line_id } & \multirow[b]{2}{*}{$\begin{array}{c}\text { Historic } \\
\text { period }\end{array}$} & \multicolumn{6}{|c|}{ Applied DG integration technique } \\
\hline & & & \multicolumn{2}{|c|}{ Coventional } & \multicolumn{2}{|c|}{ New approach } & \multicolumn{2}{|c|}{$\begin{array}{c}\text { New approach with } \\
\text { optimal NR }\end{array}$} \\
\hline \multirow{8}{*}{$\frac{n}{\vec{n}}$} & Line 5 & 0.9316 & Line 5 & 0.0971 & Line 2 & 0.0690 & Line 5 & 0.0481 \\
\hline & Line 1 & 0.9308 & Line 1 & 0.0926 & Line 5 & 0.0645 & Line 2 & 0.0461 \\
\hline & Line 2 & 0.9296 & Line 2 & 0.0793 & Line 3 & 0.0461 & Line 3 & 0.0411 \\
\hline & Line 4 & 0.9257 & Line 4 & 0.0784 & Line 4 & 0.0485 & Line 4 & 0.0409 \\
\hline & Line 7 & 0.8960 & Line 7 & 0.0735 & Line 1 & 0.0425 & Line 7 & 0.0389 \\
\hline & Line 8 & 0.8897 & Line 8 & 0.0723 & Line 7 & 0.0413 & Line 8 & 0.0385 \\
\hline & Line 3 & 0.8868 & Line 3 & 0.0705 & Line 8 & 0.0405 & Line 1 & 0.0378 \\
\hline & Line 26 & 0.8761 & Line 26 & 0.0676 & Line 26 & 0.0303 & Line 26 & 0.0376 \\
\hline \multirow{4}{*}{$\frac{n}{\vec{\sigma}}$} & Line 6 & & Line 6 & 0.0610 & Line 6 & 0.0601 & Line 6 & 0.0571 \\
\hline & Line 48 & 0.8784 & Line 5 & 0.0611 & Line 40 & 0.0586 & Line 5 & 0.0571 \\
\hline & Line 5 & 0.8775 & Line 40 & 0.0606 & Line 48 & 0.0562 & Line 48 & 0.0522 \\
\hline & \begin{tabular}{|l|} 
Line 40 \\
\end{tabular} & 0.8766 & Line 48 & 0.0591 & Line 5 & 0.0522 & Line 40 & 0.0429 \\
\hline \multirow{6}{*}{$\frac{a}{3}$} & \begin{tabular}{|l|} 
Line 64 \\
\end{tabular} & 0.8809 & Line 110 & 0.0603 & Line 64 & 0.0742 & Line 108 & 0.0525 \\
\hline & Line 110 & 0.8807 & Line 64 & 0.0586 & Line 108 & 0.0626 & Line 64 & 0.0573 \\
\hline & Line 108 & 0.8804 & Line 63 & 0.0585 & Line 110 & 0.0608 & Line 110 & 0.0535 \\
\hline & \begin{tabular}{|l|l|} 
Line 63 \\
\end{tabular} & 0.8803 & Line 108 & 0.0580 & Line 3 & 0.0577 & Line 9 & 0.0496 \\
\hline & Line 3 & 0.8798 & Line 3 & 0.0577 & Line 9 & 0.0577 & Line 3 & 0.0443 \\
\hline & Line 9 & 0.8797 & Line 9 & 0.0576 & Line 63 & 0.0570 & Line 63 & 0.0412 \\
\hline
\end{tabular}

Table VI also shows that the total loss-of-life ('historic' plus 'conventional' column) of cable sections 5, 1 and 2 in the 33-bus network is greater than unity, which means they need to be replaced in the planning period. However, if either the second or the third strategy is applied, their replacement is deferred for the next regulatory period. It can also be noticed that lower loss-of-lives are obtained when the new approach with optimal NR is used in each hour of the simulation period. 
The third strategy delivers the best results in terms of system reliability performance (Table IV), total operational costs (Table V) and cable loss-of-lives (Table VI).

Table VII presents results of cable ranking based on the new approach with optimal NR. Two case studies are investigated: the first makes use of the cost criterion (30), while the second is based on the total cost that includes the cost of cable loss-of-lives (31). Differences in costs for these two ranking schemes are not that big, because the last term in (31) represents the cost of additional ageing with respect to the pre-fault condition. We have obtained similar ranking orders of cable sections using criteria (30) and (31); however, there were differences in all test networks whenever the ranking cost figures were relatively close.

TABLE VII - CABle RANKIng BASED on: A) 'Direct' Cost, B) 'Total' Cost

\begin{tabular}{|c|c|c|c|c|}
\hline System & \multicolumn{2}{|c|}{$\mathrm{COST}_{1}$} & \multicolumn{2}{|c|}{$\mathrm{COST}_{2}$} \\
\hline \multirow{9}{*}{$\frac{\tilde{\partial}}{\tilde{e}}$} & Line 3 & $£ 42,787.97$ & Line 3 & $£ 44,167.07$ \\
\hline & Line 5 & $£ 22,412.08$ & Line 5 & $£ 23,926.79$ \\
\hline & Line 2 & $£ 17,330.69$ & Line 2 & $£ 18,841.28$ \\
\hline & Line 4 & $£ 16,650.86$ & Line 4 & $£ 18,024.77$ \\
\hline & Line 7 & $£ 14,557.19$ & Line 26 & $£ 15,889.56$ \\
\hline & Line 26 & $£ 14,442.10$ & Line 7 & $£ 15,743.78$ \\
\hline & Line 1 & $£ 11,698.13$ & Line 1 & $£ 13,013.30$ \\
\hline & Line 8 & $£ 9,363.90$ & Line 8 & $£ 10,686.85$ \\
\hline & & $£ 149,242.92$ & & $£ 160,293.41$ \\
\hline \multirow{5}{*}{$\frac{a}{a}$} & Line 6 & $£ 15,219.81$ & Line 6 & $£ 16,524.44$ \\
\hline & Line 5 & $£ 8,295.45$ & Line 5 & $£ 9,600.71$ \\
\hline & Line 40 & $£ 3,827.58$ & Line 48 & $£ 5,128.59$ \\
\hline & Line 48 & $£ 1,854.31$ & Line 40 & $£ 3,153.79$ \\
\hline & & $£ 29,197.15$ & & $£ 34,407.53$ \\
\hline \multirow{7}{*}{$\frac{a}{\partial}$} & Line 110 & $£ 20,127.68$ & Line 108 & $£ 21,523.68$ \\
\hline & Line 108 & $£ 19,125.28$ & Line 110 & $£ 20,927.25$ \\
\hline & Line 64 & $£ 12,361.48$ & Line 64 & $£ 13,801.34$ \\
\hline & Line 3 & $£ 8,082.30$ & Line 3 & $£ 9,481.89$ \\
\hline & Line 63 & $£ 7,449.20$ & Line 63 & $£ 9,160.45$ \\
\hline & Line 9 & $£ 6,335.39$ & Line 9 & $£ 7,763.07$ \\
\hline & & $£ 73,481.32$ & & $£ 82,657.69$ \\
\hline
\end{tabular}

Comparison of cable ranking orders based on traditional thermal loss-of-lives (Table VI) and proposed ranking criteria (30) and (31) (Table VII) shows that there are differences in case of all three studied networks. The same cable sections are usually on the top of the list, but their order is different. This is particularly important for companies that do not have a fixed replacement budget, or very small replacement funding. Assume it is wanted to replace the first three sections in the 33-bus network (i.e. sections 3, 5 and 2) using criterion (30); this would give avoided direct cost of $£ 82,530.74$ (figures

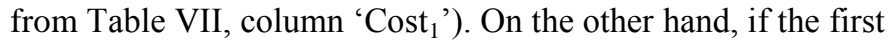
three sections in the 33-bus network are selected based on thermal loss-of-lives (sections 5, 1 and 2 in Table VI), the total avoided direct cost would have been $£ 51,440.9$. This means that the company would incur added cost of $£ 31,089.84$ in the latter case. This example shows advantage of the proposed cable ranking criteria from a utility perspective.

Additional sensitivity studies were done to find the impact of planning period length on the cable replacement ranking schemes. The planning period was varied between 5 and 8 years, which is a typical length of the price regulation period in the UK. It was assumed that there were neither new DG units, nor new network reinforcements in the added years. Variation of a single parameter, annual load growth, was studied. When the annual load increase was small (say, 1\%), the same cable ranking lists were obtained for all planning period lengths. However in case of significant annual load increases (say, >5\%), the ranking orders can be different because of changed proportions of cable loss-of-life and reliability costs. The actual length of the planning period should therefore be set to the duration of price control period, or determined by company management.

The results presented in Tables III - VII show the high impact of new DG connection points, network operation strategies and budget constraints on investment decisions. Furthermore, the findings of these studies suggest that the effective connection of wind-DG units and prioritization of distribution cables for replacement is best done when system impacts are considered in conjunction with asset stress conditions (i.e. asset ageing). These conclusions indicate that the existing real-life practice of cable replacement based on individual assets only, will need to be replaced with planning techniques that consider the overall system.

\section{CONCLUSIONS}

This paper investigates a new concept of DG integration and distribution network management whose goal is to reduce distribution cable ageing and postpone its replacement. The proposed methodology includes physical characteristics and ageing of network components, envisaged uncertainties, and different network management strategies. Two new optimization models are developed, one for optimal DG connection and the other for optimal network reconfiguration, which are incorporated within the probabilistic methodology for the analysis of the regulatory planning period. Ranking of cable sections for replacement is completed using three schemes.

The results show that simultaneous consideration of individual asset characteristics and network aspects will give the best financial results in terms of extended assets lives, increased network reliability and reduced operation costs. To this end, closer co-operation between replacement and planning teams in utilities is expected. Future studies in this area will focus on integration of other low carbon technologies (e.g. solar generation, storage, demand side management, etc.) to extend asset lives and improve network reliability. The final goal is to develop a methodology that will provide a single prioritization list of assets for both replacement and reinforcement purposes.

\section{REFERENCES}

[1] H. L. Willis and R. R. Schrieber, Aging Power Delivery Infrastructures, Second Edition: CRC Press, 2013.

[2] Y. Gill, "Development of an electrical cable replacement simulation model to aid with the management of aging underground electric cables," IEEE Electrical Insulation Magazine, vol. 27, pp. 31-37, 2011.

[3] M. D. Walton, J. T. Smith, W. A. Thue, "Accelerated Aging of Extruded Dielectric Power Cables Part I: Control and Monitoring Methodology", IEEE Transactions on Power Delivery, vol. 7, issue 2, pp. 596-602, April 1992.

[4] B. S. Bernstein, W. A. Thue, M. D. Walton, J. T. Smith, "Accelerated Aging of Extruded Dielectric Power Cables Part II: Life Testing of $15 \mathrm{kV}$ XLPE-Insulated Cables", IEEE Transactions on Power Delivery, vol. 7, issue 2, pp. 603-608, April 1992.

[5] C. Katz, G. W. Seman, B.S. Bernstein, "Low Temperature Ageing of XLPE and EP Insulated Cables with Voltage Transients", IEEE Transactions on Power Delivery, vol. 10, issue 1, pp. 34-42, January 1995. 
[6] A. K. Behera, C. E. Beck, A. Alsammarae, "Cable Aging Phenomena under Accelerated Aging Conditions", IEEE Transactions on Nuclear Science, vol. 43, issue 3, pp. 1889-1893, 1996.

[7] S. A. Boggs, "Mechanisms for Degradation of TR-XLPE Impulse Strength During Service Aging", IEEE Transactions on Power Delivery, vol. 17, issue 2, pp. 308-312, April 2002.

[8] S. B. Dalal, R. S. Gorur, M. L. Dyer, "Ageing of Distribution Cables in Service and its Simulation in Laboratory", IEEE Transactions on Dielectrics and Electrical Insulation, vol. 12, issue 1, pp. 139-146, 2005.

[9] G. Mazzanti, "Analysis of the Combined Effects of Load Cycling, Thermal Transients and Electrothermal Stress on Life Expectancy of High-Voltage AC Cables", IEEE Transactions on Power Delivery, vol. 22, issue 4, pp. 2000-2009, 2007.

[10] S. Hvidsten, S. Kvande, A. Ryen, P. B. Larsen, "Severe Degradation of the Conductor Screen of Service and Laboratory Aged Medium Voltage XLPE Insulated Cables", IEEE Transactions on Dielectrics and Electrical Insulation, vol. 16, issue 1, pp. 155-161, 2009.

[11] W. J. McNutt, G. H. Kaufmann, "Evaluation of a Functional Life Test Model for Power Transformers", IEEE Transactions on Power Apparatus and Systems, vol. PAS-102, issue 5, May 1983.

[12] C. B. Pandey, C. Lin, "Estimation for a Life Model of Transformer Insulation under Combined Electrical and Thermal Stress", IEEE Transactions on Reliability, vol. 41, issue 3, pp. 466-469, 1992.

[13] D. D. Shipp, T. J. Dionise, V. Lorch, B. G. MacFarlane, "Transformer Failure due to Circuit-Breaker-Induced Switching Transients", IEEE Transactions on Industry Applications, vol. 47, issue 2, pp. 707-718, March/April 2011.

[14] P. S. Moses, M. A. S. Masoum, "Three-Phase Asymmetric Transformer Aging Considering Voltage-Current Harmonic Interactions, Unbalanced Nonlinear Loading, Magnetic Couplings and Hysteresis", IEEE Transactions on Energy Conversion, vol. 27, issue 2, pp. 318$327,2012$.

[15] F. Edstrom, J. Rosenlind, P. Hilber, L. Soder, "Modelling Impact of Cold Load Pickup on Transformer Aging Using Ornstein-Uhlenbeck Process", IEEE Transactions on Power Delivery, vol. 27, issue 2, pp. 590-595, 2012.

[16] S. J. Tee, Q. Liu, Z.D. Wang, G. Wilson, P. Jarman, R. Hooten, D. Walker, P. Dyer, "Seasonal Influence on Moisture Interpretation for Transformer Ageing Assessment", IEEE Electrical Insulation Magazine, vol. 32, issue 3, pp. 29-37, 2016.

[17] M. Stotzel, M. Zdrallek, W. H. Wellssow, "Reliability Calculation of MV-Distribution Networks with regard to Ageing in XLPE-Insulated Cables", IEE Proceedings - Generation, Transmission and Distribution, vol. 148, issue 6, pp. 597-602, 2001.

[18] H. Kim, C. Singh, "Reliability Modelling and Simulation in Power Systems with Ageing Characteristics", IEEE Transactions on Power Systems, vol. 25, issue 1, pp. 21-28, 2010.

[19] S. Awadallah, J. Milanovic, P. Jarman, "The Influence of Modelling Transformer Age Related Failures on System Reliability", IEEE Transactions on Power Systems, vol. 30, issue 2, March 2015.

[20] A. D. Hilshey, P. D. H. Hines, P. Rezaei, J. R. Dowds, "Estimating the Impact of Electric Vehicle Smart Charging on Distribution Transformer Ageing", IEEE Transactions on Smart Grid, vol. 4, issue 2, pp. 905913, 2013.

[21] Y. O. Assolami, W. G. Morsi, "Impact of Second-Generation Plug-In Battery Electric Vehicles on the Ageing of Distribution Transformers Considering TOU Prices", IEEE Transactions on Sustainable Energy, vol. 6, issue 4, pp. 1606-1614, 2015.

[22] N. G. Paterakis, I. N. Pappi, O. Erdinc, R. Godina, E. M. G. Rodrigues, J. P. S. Catalao, "Consideration of the Impacts of a Smart Neighborhood Load on Transformer Aging", IEEE Transactions on Smart Grid, vol. 7, issue 6, pp. 2793-2802, 2016.

[23] D. J. Olsen, M. R. Sarker, M. A. Ortega-Vazquez, "Optimal Penetration of Home Energy Management Systems in Distribution Networks Considering Transformer Ageing", IEEE Transactions on Smart Grid, DOI: 10.1109/TSG.2016.2630714, 2016.

[24] M. R. Sarker, D. J. Olsen, M. A. Ortega-Vazquez, "Co-Optimization of Distribution Transformer Ageing and Energy Arbitrage Using Electric Vehicles", IEEE Transactions on Smart Grid, DOI: 10.1109/TSG. 2016.2535354, 2016.

[25] J. A. Bloom, C. Feinstein, P. Morris, "Optimal Replacement of Underground Distribution Cables", 2006 IEEE Power Systems Conference and Exposition, pp. 389-393, 2006.
[26] J. Perkel, M. Begovic, R. Hartlein, "Generating Cable Replacement Strategies Using Monte Carlo Simulation", 2006 IEEE Power Systems Conference and Exposition, pp. 2188-2193, 2006.

[27] E. Chabod, E. Dorison, T. Espilit, M. Michel, "Integrated Solution to Target MV Cable Replacement", CIRED 2009, DOI: 10.1049/cp.2009.0798, 2009.

[28] E. Duarte, D. Miller, M. Lawrence, P. Prout, J. Gavin, D. Falla, T. McGrail, "Prioritizing Transformers for Condition Based Asset Replacement", 2010 IEEE Power and Energy Society General Meeting, DOI: 10.1109/PES.2010.5590002, 2010.

[29] A. E. B. Abu-Elanien, M. M. A. Salama, R. Bartnikas, "A New Techno-Economic Replacement Technique for Transformers", 2011 IEEE Power and Energy Society General Meeting, DOI: 10.1109/PES.2011.6039479.

[30] P. Wouters, A. van Schijndel, J. M. Wetzer, "Remaining Lifetime Modelling of Power Transformers: Individual Assets and Fleets", IEEE Electrical Insulation Magazine, vol. 27, issue 3, May/june 2011.

[31] A. van Schijndel, P. Wouters, J. M. Wetzer, "Modelling Replacement Alternatives for Power Transformer Populations", IEEE Transactions on Power Delivery, vol. 27, issue 2, pp. 506-513, 2012.

[32] L. Xu, R. E. Brown, "Justifying the Proactive Replacement of Cable", 2011 IEEE Power and Energy Society General Meeting, DOI: 10.1109/PES.2011.6039491, 2011.

[33] M. Buhari, V. Levi, and S. K. E. Awadallah, "Modelling of Ageing Distribution Cable for Replacement Planning," IEEE Transactions on Power Systems, vol. 31, issue 5, pp. 3996-4004, September 2016.

[34] S. Awadallah, J. V. Milanovic, P. N. Jarman, "Reliability Based Framework for Cost-Effective Replacement of Power Transmission Equipment", IEEE Transactions on Power Systems, vol. 29, issue 5, pp. 2549-2557, 2014.

[35] P. S. Georgilakis and N. D. Hatziargyriou, "Optimal Distributed Generation Placement in Power Distribution Networks: Models, Methods, and Future Research," IEEE Transactions on Power Systems, vol. 28, pp. 3420-3428, 2013.

[36] P. S. Georgilakis and N. D. Hatziargyriou, "A review of power distribution planning in the modern power systems era: Models, methods and future research," Electric Power Systems Research, vol. 121, pp. 89-100, 2015

[37] A. Keane, L. F. Ochoa, C. L. T. Borges, G. W. Ault, A. D. AlarconRodriguez, R. A. F. Currie, F. Pilo, C. Dent, G. P. Harrison, and T. F. D. Generation, "State-of-the-Art Techniques and Challenges Ahead for Distributed Generation Planning and Optimization," IEEE Transactions on Power Systems, vol. 28, pp. 1493-1502, May 2013.

[38] R. S. Rao, K. Ravindra, K. Satish, and S. V. L. Narasimham, "Power Loss Minimization in Distribution System Using Network Reconfiguration in the Presence of Distributed Generation," IEEE Transactions on Power Systems, vol. 28, pp. 317-325, 2013.

[39] M. F. Shaaban, Y. M. Atwa, and E. El-Saadany, "DG Allocation for Benefit Maximization in Distribution Networks," IEEE Transactions on Power Systems, vol. 28, pp. 639-649, 2013.

[40] F. Capitanescu, L. F. Ochoa, H. Margossian, and N. D. Hatziargyriou, "Assessing the Potential of Network Reconfiguration to Improve Distributed Generation Hosting Capacity in Active Distribution Systems," IEEE Transactions on Power Systems, vol. 30, pp. 346-356, 2015.

[41] S. N. Gopiya Naik, D. K. Khatod, and M. P. Sharma, "Analytical Approach for Optimal siting and sizing of distributed generation in radial distribution networks," IET Generation, Transmission \& Distribution, vol. 9, pp. 209-220, 2015.

[42] H. Bagheri Tolabi, M. H. Ali, and M. Rizwan, "Simultaneous Reconfiguration, Optimal Placement of DSTATCOM, and Photovoltaic Array in a Distribution System Based on Fuzzy-ACO Approach," IEEE Transactions on Sustainable Energy, vol. 6, pp. 210-218, 2015.

[43] A. R. Jordehi, "Optimisation of electric distribution systems: A review," Renewable and Sustainable Energy Reviews, vol. 51, pp. 1088-1100, 2015.

[44] M. E. Baran and F. F. Wu, "Network Reconfiguration in DistributionSystems for Loss Reduction and Load Balancing," IEEE Transactions on Power Delivery, vol. 4, pp. 1401-1407, Apr 1989.

[45] A. Kavousi-Fard and T. Niknam, "Optimal Distribution Feeder Reconfiguration for Reliability Improvement Considering Uncertainty," IEEE Transactions on Power Delivery, vol. 29, pp. 1344-1353, 2014.

[46] M. Lavorato, J. F. Franco, M. J. Rider, and R. Romero, "Imposing Radiality Constraints in Distribution System Optimization Problems," IEEE Transactions on Power Systems, vol. 27, pp. 172-180, 2012. 
[47] M. W. Siti, D. V. Nicolae, A. A. Jimoh, and A. Ukil, "Reconfiguration and Load Balancing in the LV and MV Distribution Networks for Optimal Performance," IEEE Transactions on Power Delivery, vol. 22, pp. 2534-2540, 2007.

[48] B. Venkatesh, R. Ranjan, and H. B. Gooi, "Optimal reconfiguration of radial distribution systems to maximize loadability," IEEE Transactions on Power Systems, vol. 19, pp. 260-266, 2004.

[49] Y. K. Wu, C. Y. Lee, L. C. Liu, and S. H. Tsai, "Study of Reconfiguration for the Distribution System With Distributed Generators," IEEE Transactions on Power Delivery, vol. 25, pp. 1678$1685,2010$.

[50] N. G. Paterakis, A. Mazza, S. F. Santos, O. Erdin, G. Chicco, A. G. Bakirtzis, and J. P. S. Catal, "Multi-Objective Reconfiguration of Radial Distribution Systems Using Reliability Indices," IEEE Transactions on Power Systems, vol. 31, pp. 1048-1062, 2016.

[51] P. H. G. Alleb and A. Tustin, "The Aging Process in Electrical Insulation: A Tutorial Summary," IEEE Transactions on Electrical Insulation, vol. EI-7, pp. 153-157, 1972.

[52] R. Billinton and W. Li, Reliability Assessment of Electrical Power Systems Using Monte Carlo Methods: Springer, 1994.

[53] C. Grigg, P. Wong, P. Albrecht, R. Allan, M. Bhavaraju, R. Billinton, Q. Chen, C. Fong, S. Haddad, S. Kuruganty, W. Li, R. Mukerji, D. Patton, N. Rau, D. Reppen, A. Schneider, M. Shahidehpour, and C. Singh, "The IEEE Reliability Test System-1996. A Report Prepared by the Reliability Test System Task Force of the Application of Probability Methods Subcommittee," IEEE Transactions on Power Systems, vol. 14, pp. 1010-1020, 1999.

[54] R. Billinton and H. Dange, "Incorporating Wind Power in Generating Capacity Reliability Evaluation Using Different Models," IEEE Transactions on Power Systems, vol. 26, pp. 2509-2517, 2011.

[55] B. I. British Standards, "Electric Cables - Calculation of the current rating, BS IEC 60287-1-1:2006," in Calculation of current rating, ed. London: BSI, 2006.

[56] CEI/IEC, "Calculation of the Cyclic and Emergency Current Rating of Cables; Part 2: Cyclic Rating of Cables greater than 18/30 (36) kV and Emergency Ratings for Cables of all Voltages," vol. 60853-2:1989, ed. IEC: IEC, 1989.

[57] National Grid, "National Grid's Stand-Alone DCLF ICRP TNUoS Great Britain Transport \& Tariff Model," National Grid GB, UK2011.

[58] "Distribution Connection and Use of System Agreement" - Schedule 16: Common Distribution Charging Model", version 4.6, October 2016.

[59] Electricity North West Limited, "Regulatory Contract 2010-2015", Manchester, UK, April 2016.

[60] D.Zhang, Z.Fu, and L.Zhang, "An improved TS algorithm lossminimum reconfiguration in large scale distribution systems", Electric Power Systems Research, vol. 77, pp. 685-694, April 2007.

[61] UK Transmission Licenses, "Network Output Measures Methodology", National Grid, SP Transmission Plc, Scottish Hydro Electricity Transmission Ltd, October 2015.

[62] "Hypothetical Incremental Distribution Asset Model (HIDAM) - User Manual", Association of GB distribution companies, March 2013.

[63] AIMMS 4.13, AIMMS B.V., Haarlem, The Netherlands, 2015; software available at http://www.aimms.com/.

[64] London Economics, "The Value of Lost Load (VoLL) for Electricity in Great Britain: Final report for OFGEM and DECC," 2013.

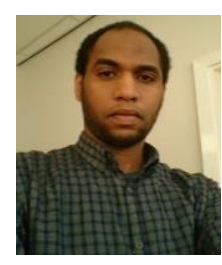

Muhammad Buhari (S'12) received the BEng and MEng degrees in electrical engineering from Bayero University, Kano, Nigeria, in 2006 and 2011, respectively. He also has an MSc in entrepreneurship and electrical and electronics engineering from The University of Nottingham, UK., in 2010.

Recently (2016) he has completed a Ph.D. degree at The University of Manchester, UK.

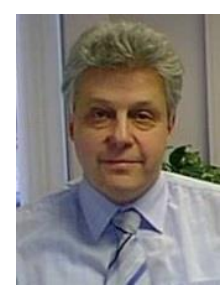

Victor Levi (S'89-M'91-SM'13) received the M.Sc. and Ph.D. degrees in electrical engineering from the University of Belgrade, Belgrade, Yugoslavia, in 1986 and 1991, respectively. From 1982 to 2001, he was with University of Novi Sad, Novi Sad, Yugoslavia, where he became a Full Professor in 2001. He was with the University of Manchester, Manchester, U.K. from 2001 to 2003, and then with United Utilities and Electricity North West, from 2003 to 2013. In 2013, he rejoined the University of Manchester.

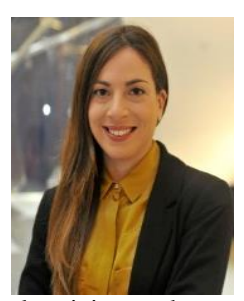

Alexandra Kapetanaki (S'12) received the MEng degree in electrical engineering and computer science from the National Technical University of Athens (NTUA), Greece, in 2011. She is completing the Ph.D. studies at the Electrical Energy and Power Systems Group at The University of Manchester. She currently works as an energy consultant at Arup, where she specialises in optimization for power system operation, low carbon technologies, risk management and 